\title{
Politique
}

Politique

Devant l'histoire. Les documents de la controverse sur la singularité de l'extermination des Juifs par le régime nazi. coll. " Passages », Les Édiitions du CERF, Paris, 1988, 353 p.

\section{Roger Charland}

Numéro 14, automne 1988

Sport et politique et Le NPD

URI : https://id.erudit.org/iderudit/040612ar

DOI : https://doi.org/10.7202/040612ar

Aller au sommaire du numéro

Éditeur(s)

Société québécoise de science politique

ISSN

0711-608X (imprimé)

1918-6584 (numérique)

Découvrir la revue

Citer ce compte rendu

Charland, R. (1988). Compte rendu de [Devant l'histoire. Les documents de la controverse sur la singularité de l'extermination des Juifs par le régime nazi. coll. " Passages », Les Éditions du CERF, Paris, 1988, 353 p.] Politique, (14), 194-198. https://doi.org/10.7202/040612ar d'utilisation que vous pouvez consulter en ligne.

https://apropos.erudit.org/fr/usagers/politique-dutilisation/ 
Devant l'histoire. Les documents de la controverse sur la singularité de l'extermination des Juifs par le régime nazi. coll. «Passages», Les Éditions du CERF, Paris, 1988, 353 p.

La publication en français de ce débat est importante. La cicarrice dans l'histoire allemande du passé national-socialiste demeure très profonde. L'interrogation des intellectuels repose avant tout sur la possibilité ou non de transgresser ce passé. Les intervenants de ce débat sur le national-socialisme ne nient pas l'existence des chambres à gaz et des crématoires. Fondamentalement, les révisionistes allemands tentent de sauver «l'identité nationale allemande». Pour parvenir à cette fin, ils soutiennent que 
l'extermination des Juifs est comparable à l'extermination des Ukrainiens, des Cambodgiens, etc.

Ainsi la principale cible des révisionistes allemands est le socialisme "réellement existant» et la sauvegarde de l'identité prussienne, le fondement d'une Europe centrale autonome. Cette volonté de développement d'une identité'centre-européenne estelle un prétexte servant à minimiser les actions des nationaux socialistes et la passivité du peuple allemand devant leurs crimes?

Les historiens révisionistes ne se gênent aucunement de l'appel qu'ils font d'un passé national mythique. Voici en quelques lignes les contours du débat. Nous croyons important de le déconstruire pour saisir la logique défendue d'une légitimation du passé nazi.

Dans un premier temps, il est important de noter que les intervenants dans ce débat sont des intellectuels réputés, chacun dans leurs spécialités. Bien que cette discussion résulte d'interprétations remettant en cause le caractère unique des crimes du national-socialisme, il se situe aussi ailleurs. Il vise la déculpabilisation de la nation allemande. Les théoriciens allemands du révisionisme pensent avant tout qu'il est nécessaire de redonner au peuple allemand sa fierté. Le passé national-socialiste, suivant en celà l'historien Nolte, ne serait qu'une réaction au crime soviétique, donc au crime asiatique. (p. 33) Soutenant l'idée qu'Auchwitz est un obstacle au rétablissement d'une conscience nationale allemande, les révisionistes allemands fixent les paramètres visant la dissolution de leurs responsabilités eu égard au génocide juif. En ce sens, ils avancent l'idée que l'extermination des Juifs s'excuse par l'identification que le national-socialisme soutenait d'un danger socialiste propre aux Juifs. Notons que ce raisonnement trouve son déploiement dans l'idée qu'Auschwitz n'est qu'un produit de la crise européenne. Dès lors la responsabilité allemande est réduite à une supposée objectivité historique et fait de ce phénomène un accident particulier de l'histoire. 
Pour les historiens révisionistes allemands, les nazis n'ont pas le monopole de l'horreur. Le communisme russe serait dès lors un régime qualitativement plus horrible. La singularité des camps d'extermination y est exclue. La gazification des Juifs est alors un événement historique fâcheux et regrettable mais, il n'est pas autre chose qu'un moment historique parmi tant d'autres. En somme la supposée objectivité historique excuse le génocide.

Dans un deuxième temps, il nous faut relever cette prétention qu'ont les révisionistes de vouloir ramener l'histoire à une marche progressive visant la construction d'une identité allemande. C'est sur ce point précis qu'Habermas entre dans la discussion, car à son avis l'identité allemande ne peut se saisir elle-même sans conserver une conscience aigu de son passé national-socialiste. Comme l'indique bien Joseph Rovan en introduction, certaines causes expliquent la crise que connaît l'interprétation du nazisme et des crimes commis en son nom. Reprenons ici certains éléments propre à la conjoncture du débat pour en éclairer les enjeux.

Nous sommes rendus à la deuxième génération d'Allemands depuis la dernière guerre. L'héritage est saisie par la génération qui participe à ce débat comme quelque chose de singulier. Ils sont les enfants du nazisme. Pour les conservateurs cette période devrait maintenant appartenir au passé. Elle n'est plus un phénomène actuel ou actualisé. La période du national-socialisme ne peux pas composer avec l'identité d'une Allemagne moderne. Les conservateurs ne veulent pas être héréditairement coupables de ces meurtres. En somme l'Allemagne n'a plus de rapports directs avec le national-socialisme. Il faudrait que toute l'histoire allemande puisse être réécrite en faisant du national-socialisme un phénomène qui ne se serait pas instauré et maintenu uniquement grâce à un sourien actif ou passif du peuple allemand.

Il faut se rappeler que la République Démocratique d'Allemagne, dès sa fondation, a tenté de chercher dans l'histoire les fondements de son orientation socialiste. Bien qu'au débat la 
RDA pouvait trouver les moyens conjoncturels pour légirimer le système politique communiste, il semble qu'aujourd'hui le recours à l'histoire pose problème. L'appel à des faits et traditions historiques visant la constitution et la légitimation d'un système politique particulier, dans ce cas si le socialisme, au dépend de la totalité historique, est un risque. En fait vouloir à tout prix fixer l'hégémonie d'un État grâce à l'appel d'événements historiques risque de se retourner contre ceux qui soutiennent de telles tentatives. Ce phénomène est particulièrement vrai dans la situation de l'Allemagne de l'Est. Rappelons cette phrase de Michaël Stürmer: «Tout est possible dans un pays sans mémoire».

Ce débat, dans une autre situation que celle des deux Allemagnes, aurait sans doute eu une importance bien moins grande. Mais dans cette situation, les débats intellectuels sont toujours très près des luttes politiques. D'ailleurs cette discussion semble prendre pied dans les conflits politiques qui opposent la social-démocratie (Habermas et autres) et les conservateurs (Stürmer par exemple). "Pour les hommes et les femmes de cette gauche culturelle, la droite qui revenait au pouvoir à l'automne 1982 portait toujours les marques d'un passé de compromis et de compromissions avec le nazisme dont les fondements, à leurs yeux, sont toujours dans la République fédérale». (p. XXIV) Il s'agit bien sûr d'un débat de méthode et de traitement des phénomènes historiques, mais ces derniers semblent servir des visés politiques différentes. Ainsi, au débat entre les deux Allemagnes, se juxtapose la lutte politique de la RFA par le biais des intellectuels et le problème de la conscience allemande à l'Est.

Le débat comme nous l'avons vu repose sur l'interprétation du passé naziste. D'un côté il y a les thèses de Nolte et de plusieurs autres qui tentent de «noyer les crimes hitlériens dans la masse des génocides et massacres qui accompagnent la marche de l'histoire universelle». (p. XXV) Nolte juxtapose l'extermination des Juifs à d'autres phénomènes historiques, dont le bolchévisme. En réaction 
à cette vision, Habermas, loin d'amoindrir l'importance du stalisnisme, ne croit pas que l'on puisse enlever au génocide juif sa particularité. En somme, Habermas considère que la présence dans l'histoire de crimes de ce genre ne peut aucunement être utilisée pour diminuer ce qu'a été l'Holocauste.

Il faut éviter de croire, comme Hagen Schulze l'écrit, que chaque moment historique renferme un moment d'unicité et de singularité, donc que tous les phénomènes historiques se valent l'un et l'autre. Eberhard Jäckel répond à ce relativisme historique que: “jamais auparavant un État n'avait décidé et annoncé sous l'autorité de son responsable suprême qu'un certain groupe humain devait être exterminé autant que possible dans sa totalité, les vieux, les femmes, les enfants et les nourrissons inclus». (p. 9798)

En somme Devant l'bistoire est un livre précieux. D'un côté il réactualise les débats concernant l'héritage national-socialiste, et de l'autre il permet de saisir le pouls politique et social des deux Allemagnes.

Roger Charland

Université de Montréal 